\title{
Sediment Graphs Based on Entropy Theory
}

\author{
Vijay P. Singh, F.ASCE${ }^{1}$; Huijuan Cui ${ }^{2}$; and Aaron Byrd ${ }^{3}$
}

\begin{abstract}
Using the entropy theory, this paper derives an instantaneous unit sediment graph (IUSG or USG) to determine sediment discharge and the relation between sediment yield and runoff volume. The derivation of IUSG requires an expression of the effective sediment erosion intensity whose relation with rainfall is revisited. The entropy theory provides an efficient way to estimate the parameters involved in the derivations. Sediment discharge is also computed using the instantaneous unit hydrograph (IUH), which can also be derived using the entropy theory. This method works as well as the IUSG method, especially when the peak sediment discharge and peak runoff occur at the same time. The entropy theory yields the probability distribution of sediment yield and of sediment discharge, which can then be used to estimate uncertainty in sediment yield prediction. DOI: 10.1061/(ASCE)HE.1943-5584.0001068. @ 2014 American Society of Civil Engineers.
\end{abstract}

Author keywords: Entropy theory; Sediment yield; Sediment discharge; Unit hydrograph; Unit sediment graph.

\section{Introduction}

Sediment yield from a watershed depends on rainfall characteristics (amount, intensity, duration, and spatiotemporal distribution), soil characteristics (texture, structure, porosity, and spatial variability), land use, slope, and anthropogenic factors. Sediment yield models can be classified into three groups: (1) lumped, (2) quasi-lumped, and (3) distributed.

Perhaps the most popular lumped model for computing sediment yield from small watersheds (agricultural, forest, and urban) is the Universal Soil Loss Equation (USLE) developed by Wischmeier and Smith (1978). Williams (1975) and Williams and Berndt (1977) modified USLE by explicitly including the effect of runoff and designated it as MUSLE. Later Renard et al. (1993) further revised it and called it the revised USLE (RUSLE). To apply USLE to large watersheds, the concept of delivery ratio (ratio of sediment generated to the amount of erosion) has been incorporated. Another lumped model is based on the soil conservation service curve number (SCS-CN) method (Soil Conservation Society of America 1977). Tyagi et al. (2008) extended the SCS-CN method for determining sediment yield from agricultural watersheds. The empirical and lumped sediment yield models have been found to yield satisfactory results for watersheds where needed data are available but have limited capability for ungauged watersheds.

Quasi-lumped or conceptual sediment yield models are based on the hydrologic systems approach that became popular in the 1970s and 1980s. Popular examples include sediment graph and unit sediment graph (USG) models. The sediment graph model

${ }^{1}$ Distinguished Professor and Caroline \& William N. Lehrer Distinguished Chair in Water Engineering, Dept. of Biological and Agricultural Engineering, Dept. of Civil and Environmental Engineering, Texas A \& M Univ., College Station, TX 77843-2117.

${ }^{2}$ Graduate Student, Water Management and Hydrologic Science Program, Texas A \& M Univ., College Station, TX 77843-2117 (corresponding author). E-mail: cui.huijuan@gmail.com

${ }^{3}$ Research Hydraulic Engineer and Branch Chief, Hydrologic Systems Branch, Coastal and Hydraulics Laboratory, Engineer Research Development Center, U.S. Army Corps of Engineers, Vicksburg, MS 39181.

Note. This manuscript was submitted on March 25, 2014; approved on July 17, 2014; published online on August 20, 2014. Discussion period open until January 20, 2015; separate discussions must be submitted for individual papers. This paper is part of the Journal of Hydrologic Engineering, (C) ASCE, ISSN 1084-0699/C4014004(10)/\$25.00. was proposed by Rendon-Herrero (1974) and further investigated by Rendon-Herrero et al. (1980) and Singh and Chen (1982). Rendon-Herrero $(1974,1978)$ extended the unit hydrograph (UH) method to directly derive the unit sediment graph for a small watershed. Williams (1978) and Chen and Kuo (1986) extended the concept of UH or instantaneous unit hydrograph (IUH) to derive the instantaneous unit sediment graph (IUSG) and then determined sediment discharge and yield from agricultural watersheds. Singh et al. (1982), Chen and Kuo (1986), Srivastava et al. (1984), among others, employed USG or IUSG. Sharma and Dickinson (1979a, b) developed a conceptual model for daily and monthly sediment yield. These models have been shown to be satisfactory but have not been applied as extensively as USLE or its variants.

To overcome the limitations of conceptual, lumped, or empirical models, a number of physically based models have been developed incorporating the hydraulics of flow of water and sediment (detachment, suspension, deposition, and transport) (Foster and Lane 1983; Lane and Nearing 1989; Singh 1983, 1989; Singh and Regl 1983; Hairsine and Rose 1992; Jin et al. 1999). These physically (or process)-based models enhance one's understanding of the mechanics of erosion and sediment transport, but it is difficult to estimate their parameters for ungauged or large watersheds. To overcome this limitation, the process-based models have been coupled with watershed hydrology models, such as KINEROS (Smith et al. 1995), SHETRAN (Figueiredo and Bathurst 2007), EUROSEM (Morgan et al. 1998), MEDRUSH (Kirkby et al. 2002), and MODFSRS (Nunes et al. 2006). These models also have not been widely accepted, largely because of data requirements.

The aforementioned models are deterministic. Although erosion and sediment transport are subject to considerable uncertainty, these models have not been modified to account for this uncertainty. Singh and Krstanovic (1987) developed a stochastic model for sediment yield using the principle of uncertainty. Their model is lumped and is mathematically complicated. De Araujo (2007) was perhaps the first to develop a hillslope sediment production equation accounting for this uncertainty by applying the entropy theory, but his model needs verification.

It is desirable to keep the simplicity of lumped and conceptual models but incorporate uncertainty. Therefore, the objective of this paper is to derive sediment graph models using entropy theory and evaluate these models with data from agricultural watersheds. 


\section{Sediment Graph Models}

For a given storm, let water discharge and sediment discharge at the watershed outlet at time $t$ be denoted respectively by $Q(t)$ and $Q_{s}(t)$. Let the amount of surface runoff for a given storm (or rainfall excess) be denoted by $V_{p}$ and the sediment yield or wash load by $y$. Then

$$
V_{p}=\int_{0}^{\infty} Q(t) d t
$$

and

$$
y=\int_{0}^{\infty} Q_{s}(t) d t
$$

Of course, sediment discharge is the product of spatially averaged sediment concentration, $c(t)$, and water discharge and can be expressed as

$$
Q_{s}(t)=c(t) Q(t)
$$

In the literature, sediment graph models have been developed in two interrelated ways. First, empirical relations between $y$ given by Eq. (2) and $V_{p}$ given by Eq. (1) have been developed. Second, the unit hydrograph theory has been applied to determine $Q(t)$; multiplying it by sediment concentration determined using an empirical or a conceptual approach yields $Q_{s}(t)$. In another way, IUSG is determined and then sediment discharge is directly determined. The purpose here is to show that these models can be derived by applying the entropy theory. The advantage of the entropy theory is that the probability distribution of sediment yield or discharge can be explicitly specified, and hence the uncertainty thereof can be specified.

\section{Sediment Yield-Runoff Relation}

Rendon-Herrero (1974) suggested a linear relation on logarithmic paper between sediment yield (wash load) and surface runoff volume due to rainfall from small upland watersheds. He hypothesized that the slope of this straight line would remain approximately constant from one watershed to another. An investigation by Singh and Chen (1982) of 39 watersheds from 14 states in the United States concluded that the linear relationship was satisfactory for a number of watersheds; the relationship improved if the storms were separated into winter and summer storms, excluding snow storms; and the intercept would reflect the individual watershed characteristics. The relation between sediment yield $(y)$ and volume of surface runoff $\left(V_{Q}\right)$ can be expressed as

$$
y=a V_{Q}^{b}
$$

or

$$
\log y=\log a+b \log V_{Q}
$$

where $a$ and $b$ are parameters.

\section{Derivation of Sediment Graph by Entropy Theory}

To derive a sediment graph using entropy theory, it is assumed that temporally averaged sediment yield $Y$ is a random variable with a probability density function (PDF) denoted by $f(y)$. The Shannon (1948) entropy of $Y$, or of $f(y), H(Y)$, can be expressed as

$$
H(Y)=-\int_{0}^{\infty} f(y) \ln f(y) d y
$$

Eq. (5) expresses a measure of uncertainty about $f(y)$ or the average information content of sampled $y$. The objective here is to derive the least-biased $f(y)$, which can be accomplished by maximizing $H(Y)$, subject to specified constraints, in accordance with the principle of maximum entropy (POME). Maximizing $H(y)$ is equivalent to maximizing $[-f(y) \ln f(y)]$. To determine the $f(y)$ that is least biased toward what is not known as regards sediment yield, POME, developed by Jaynes (1957a, b, 1982), is invoked, which requires the specification of certain information, expressed in terms of what is called constraints, on sediment yield. According to POME, the most appropriate probability distribution is the one that has the maximum entropy or uncertainty, subject to these constraints.

\section{Specification of Constraints}

To derive the sediment graph, constraints can be specified in a general manner (Singh 1998). However, to keep the analysis simple, constraints can simply be specified as

$$
C_{1}=\int_{0}^{\infty} f(y) d y=1
$$

and

$$
C_{2}=\int_{0}^{\infty}[\ln y] f(y) d y=\overline{\ln y}
$$

Eq. (6) is the first constraint defining the total probability law, $C_{1}$, and Eq. (7) is the second constraint $C_{2}$ defining the mean of the logarithm of sediment yield values.

\section{Maximization of Entropy}

To obtain the least-biased probability density function of $Y, f(y)$, the Shannon entropy, given by Eq. (5), is maximized following POME, subject to Eqs. (6) and (7). To that end, the method of Lagrange multipliers is employed. The Lagrangian function then becomes

$$
\begin{aligned}
L= & -\int_{0}^{\infty} f(y) \ln f(y) d y-\left(\lambda_{0}-1\right)\left[\int_{0}^{\infty} f(y) d y-C_{1}\right] \\
& -\lambda_{1}\left[\int_{0}^{\infty} \ln y f(y) d y-C_{2}\right]
\end{aligned}
$$

where $\lambda_{0}$ and $\lambda_{1}=$ Lagrange multipliers. Recalling the EulerLagrange equation of calculus of variation, differentiating Eq. (8) with respect to $f$, noting that $f$ is a variable and $y$ a parameter, and equating the derivative to zero, one obtains

$$
\frac{\partial L}{\partial f}=0=-[\ln f(y)+1]-\left(\lambda_{0}-1\right)-\lambda_{1} \ln y
$$

\section{Derivation of Probability Distribution}

Eq. (9) leads to the entropy-based PDF of sediment yield as a power law as

$$
f(y)=\exp \left(-\lambda_{0}-\lambda_{1} \ln y\right) \quad \text { or } \quad f(y)=\exp \left(-\lambda_{0}\right) y^{-\lambda_{1}}
$$

The PDF of $Y$ contains the Lagrange multipliers $\lambda_{0}$ and $\lambda_{1}$, which can be determined using Eqs. (6) and (7). The cumulative 
probability distribution function of $Y$ can be obtained by integrating Eq. (10) as

$$
F(y)=\frac{\exp \left(-\lambda_{0}\right)}{-\lambda_{1}+1} y^{-\lambda_{1}+1}
$$

\section{Maximum Entropy}

Substitution of Eq. (10) into Eq. (5) yields the maximum entropy or uncertainty of sediment yield

$$
H(Y)=\lambda_{0}+\lambda_{1} \overline{\ln y}
$$

\section{Determination of Lagrange Multipliers}

Substitution of Eq. (10) into Eq. (6) leads to

$$
\lambda_{0}=-\ln \left(-\lambda_{1}+1\right)+\left(-\lambda_{1}+1\right) \ln \left[y_{D}\right]
$$

where $y_{D}=$ maximum value of $y$. Differentiating Eq. (13) with respect to $\lambda_{1}$ produces

$$
\frac{\partial \lambda_{0}}{\partial \lambda_{1}}=\frac{1}{-\lambda_{1}+1}-\ln y_{D}
$$

On the other hand, substitution of Eq. (10) into Eq. (6) can also be written as

$$
\lambda_{0}=\ln \int_{0}^{y_{D}} y^{-\lambda_{1}} d y
$$

Differentiating Eq. (15) with respect to $\lambda_{1}$, one obtains

$$
\frac{\partial \lambda_{0}}{\partial \lambda_{1}}=-\frac{\int_{0}^{y_{D}}(\ln y) y^{-\lambda_{1}} d y}{\int_{0}^{y_{D}} y^{-\lambda_{1}} d y}
$$

Multiplying and dividing Eq. (16) by $\exp \left(-\lambda_{0}\right)$ and using Eq. (6) yields

$$
\frac{\partial \lambda_{0}}{\partial \lambda_{1}}=-\frac{\int_{0}^{y_{D}}(\ln y) \exp \left(-\lambda_{0}\right) y^{-\lambda_{1}} d y}{\int_{0}^{y_{D}} \exp \left(-\lambda_{0}\right) y^{-\lambda_{1}} d y}=-\overline{\ln y}
$$

Equating Eq. (17) to Eq. (14), an expression for $\lambda_{1}$ is obtained in terms of the constraint and the limits of integration of $Q$ as

$$
\lambda_{1}=1-\frac{1}{\ln y_{D}-\overline{\ln y}}
$$

\section{Derivation of Sediment Graph}

Let the maximum runoff volume be denoted by $V_{P}$. It is then assumed that all values of sediment yield $y$ measured at the watershed outlet for any storm between 0 and $V_{P}$ are equally likely. In reality, this is not highly likely because at different times different values of sediment yield do occur. This is also consistent with the Laplacian principle of insufficient reason. Then the cumulative probability distribution of sediment yield can be expressed as the ratio of surface runoff volume to the maximum surface runoff volume. The probability of the sediment yield's being equal to or less than a given value of $y$ is $V_{Q} / V_{P}$; for any surface runoff volume (measured at the outlet) less than a given value, $V_{Q}$, the sediment yield is less than a given value, say $y$; thus the cumulative distribution function of sediment yield, $F(y)=P$ (sediment yield $\leq$ a given value of of $y$ ), $P=$ probability, can be expressed as

$$
F(y)=\frac{V Q}{V_{P}}
$$

$F(Y)$ denotes the cumulative distribution function (CDF) of sediment yield. It should be noted that on the left-hand side the argument of function $F$ in Eq. (19) is variable $y$, whereas on the right-hand side the variable is $V_{Q}$. The CDF of $Y$ is not linear in terms of $V_{Q}$, unless $Y$ and $V_{Q}$ are linearly related. Of course, it is plausible that $F(y)$ might have a different form. Since Eq. (19) constitutes the fundamental hypothesis employed here for deriving the sediment graph using entropy, it will be useful to evaluate its validity. This hypothesis [i.e., the relation between the cumulative probability $F(y)$ and the ratio $V_{Q} / V_{P}$ ] should be tested for a large number of natural watersheds. It may also be noted that a similar hypothesis has been employed when using the entropy theory to derive infiltration equations by Singh (2010a, b), soil moisture profiles by Singh (2010c), and velocity distributions by Chiu (1987).

The PDF is obtained by differentiating Eq. (19) with respect to $Y$

$$
f(y)=\frac{d F(y)}{d y}=\frac{1}{V_{P}} \frac{d V_{Q}}{d y} \quad \text { or } \quad f(y)=\left(V_{P} \frac{d y}{d V_{Q}}\right)^{-1}
$$

The term $f(y) d y=F(y+d y)-F(y)$ denotes the probability of the sediment yield's being between $y$ and $y+d y$.

Substituting Eq. (10) into Eq. (20) yields

$$
\left.\frac{\exp \left(-\lambda_{0}\right)}{-\lambda_{1}+1} y^{-\lambda_{1}+1}\right|_{0} ^{y}=\left.\frac{1}{V_{P}} V_{Q}\right|_{0} ^{V_{Q}}
$$

Eq. (21) yields

$$
y=\left[\frac{\exp \left(\lambda_{0}\right)\left(-\lambda_{1}+1\right)}{V_{P}} V_{Q}\right]^{\left[1 /\left(-\lambda_{1}+1\right)\right]}=a V_{Q}^{b}
$$

where

$$
a=\left[\frac{\exp \left(\lambda_{0}\right)}{V_{P}}\left(-\lambda_{1}+1\right)\right]^{\left[1 /\left(-\lambda_{1}+1\right)\right]}
$$

and

$$
b=\frac{1}{-\lambda_{1}+1}
$$

Eq. (22) is an expression of the sediment graph and is the same as Eq. (4a). When plotted on log-log paper, Eq. (22) will be a straight line. It may now be interesting to evaluate the Lagrange multipliers and hence parameters $a$ and $b$.

\section{Determination of Lagrange Multipliers}

Substitution of Eq. (10) into Eq. (5) yields

$$
\begin{aligned}
\exp \left(\lambda_{0}\right) & =\frac{y_{D}^{-\lambda_{1}+1}}{-\lambda_{1}+1} \text { or } \\
\lambda_{0} & =-\ln \left(-\lambda_{1}+1\right)+\left(-\lambda_{1}+1\right) \ln \left(y_{D}\right)
\end{aligned}
$$

where $y_{D}=$ sediment yield when $V_{Q}=V_{P}$.

Differentiating Eq. (25) with respect to $\lambda_{1}$, one obtains

$$
\frac{\partial \lambda_{0}}{\partial \lambda_{1}}=-\ln y_{D}+\frac{1}{-\lambda_{1}+1}
$$


One can also write from Eqs. (10) and (5)

$$
\lambda_{0}=\ln \int_{0}^{y_{D}} y^{-\lambda_{1}} d y
$$

Differentiating Eq. (27) with respect to $\lambda_{1}$ and simplifying, one obtains

$$
\frac{\partial \lambda_{0}}{\partial \lambda_{1}}=-\overline{\ln y}
$$

Equating Eq. (28) to Eq. (26) leads to an estimate of $\lambda_{1}$

$$
\lambda_{1}=1-\frac{1}{\ln y_{D}-\overline{\ln y}}
$$

Therefore, exponent $b$ of Eq. (4a) becomes

$$
b=\ln y_{D}-\overline{\ln y}
$$

Eq. (30) shows that exponent $b$ of the power form sediment graph can be estimated from the values of the logarithm of maximum sediment yield corresponding to the maximum surface runoff volume and the average of the logarithmic values of sediment yield. The higher the difference between these logarithm values, the higher will be the exponent.

The Lagrange multiplier $\lambda_{0}$ can now be expressed as

$$
\lambda_{0}=\frac{\ln y_{D}}{\ln y_{D}-\overline{\ln y}}+\ln \left(\ln y_{D}-\overline{\ln y}\right)
$$

Therefore,

$$
a=\left\{\frac{\exp \left[\ln y_{D} /\left(\ln y_{D}-\overline{\ln y}\right)\right]}{V_{P}}\right\}^{\ln y_{D}-\overline{\ln y}}
$$

The PDF of $Y$ can now be expressed as

$$
f(y)=\exp \left(-\lambda_{0}\right) y^{(1 / b)-1}=\frac{\exp \left[-\ln y_{D} /\left(\ln y_{D}-\overline{\ln y}\right)\right]}{\ln y_{D}-\overline{\ln y}} y^{(1 / b)-1}
$$

and the $\mathrm{CDF}$ as

$$
F(y)=b \exp \left(-\lambda_{0}\right) y^{1 / b}=\exp \left[-\ln y_{D} /\left(\ln y_{D}-\overline{\ln y}\right)\right] y^{1 / b}
$$

For $b<1$, the PDF monotonically increases from 0 to $\exp \left(-\lambda_{0}\right) y_{D}^{(1 / b)-1}$.

The entropy (in Napiers) of the sediment yield distribution can be obtained by substituting Eq. (33) into Eq. (5)

$$
\begin{aligned}
H & =\lambda_{0}-\left(\frac{1}{b}-1\right) \overline{\ln y} \\
& =-\frac{\ln y_{D}}{\ln y_{D}-\overline{\ln y}}+\ln \left[\ln y_{D}-\overline{\ln y}\right]-\left(\frac{1}{b}-1\right) \overline{\ln y}
\end{aligned}
$$

\section{Unit Sediment Graph}

It may be useful to recall the UH and USG. The UH is the distribution of runoff due to a unit amount of rainfall excess of one unit duration occurring uniformly over a watershed. Clearly, the amount of runoff generated is unity and its time distribution is a UH. Here, the input to the watershed is rainfall, but abstractions are subtracted and rainfall excess of uniform intensity is determined. The runoff thus generated is surface runoff. Analogously, USG can be defined as the distribution of sediment due to the unit amount of effective erosion amount of one unit duration that is generated uniformly over a watershed. The term effective erosion implies that the eroded sediment that gets trapped during the course of its travel from the point of generation to the watershed outlet is subtracted, and the effective erosion amount is what constitutes the sediment yield, which is essentially wash load. The effective erosion amount is the integral of effective erosion intensity, and, analogously to rainfall excess intensity, the effective erosion intensity is uniform over its unit duration. The unit amount of effective erosion is generated by the unit amount of rainfall excess, and they are both assumed to occur uniformly over the watershed. If the unit duration tends to be infinitesimally small, then the resulting UH and USG will become IUH and IUSG, respectively.

Let $I(t)$ denote the rainfall excess intensity, and let $h(t)$ denote IUH. Then the UH theory yields runoff hydrograph as

$$
Q(t)=\int_{0}^{t} h(t-\tau) I(\tau) d \tau
$$

In a similar manner, if the effective sediment erosion intensity (ESEI), $E(t)$, denotes the amount of sediment erosion per unit of time and $h_{s}(t)$ denotes IUSG, then the sediment discharge at any time $t$, denoted by $Q_{s}(t)$, can be written as

$$
Q_{s}(t)=\int_{0}^{t} h_{s}(t-\tau) E(\tau) d \tau
$$

\section{Determination of IUH by Entropy Theory}

The UH is now determined by the entropy theory. Depending on the constraints, entropy maximizing yields different expressions for IUH. Let the constraints be expressed as

$$
\begin{gathered}
\int_{0}^{\infty} \ln t h(t) d t=\overline{\ln t} \\
\int_{0}^{\infty} t^{c} h(t) d t=\overline{t^{c}}
\end{gathered}
$$

where $c$ is an exponent, an empirical parameter that can still be related to the hydraulics of flow. Eq. (38) expresses the expectation of the log values of times of travel or the mean travel time in the logarithmic domain, whereas Eq. (39) expresses the moment of time of travel raised to a power $c$. If, for example, $c$ equals 1 , then Eq. (39) expresses the mean travel time or the first moment about the origin; if $c$ equals 2, then it expresses the second moment about the origin (equal to the variance of time of travel minus the square of mean travel time), and so on.

Entropy maximizing, subject to Eqs. (38) and (39) as well as the total probability, leads to

$$
\begin{aligned}
h(t) & =\frac{c \lambda_{2}^{\left(1-\lambda_{1}\right) / c}}{\Gamma\left(\frac{1-\lambda_{1}}{c}\right)} \exp \left(-\lambda_{1} \ln t-\lambda_{2} t^{c}\right) \\
& =\frac{c \lambda_{2}^{\left(1-\lambda_{1}\right) / c}}{\Gamma\left(\frac{1-\lambda_{1}}{c}\right)} t^{-\lambda_{1}} \exp \left(-\lambda_{2} t^{c}\right)
\end{aligned}
$$

Eq. (40) has three parameters: $\lambda_{1}, \lambda_{2}$, and $c$. Exponent $c$ can be either specified or determined by trial and error or estimated using the entropy method. Parameters $\lambda_{1}, \lambda_{2}$, and $c$ are determined using the entropy theory (Singh 2011) as

$$
\frac{\ln \lambda_{2}}{c}-\frac{1}{\Gamma\left[\left(1-\lambda_{1}\right) / c\right]} \frac{\partial \Gamma\left[\left(1-\lambda_{1}\right) / c\right]}{\partial \lambda_{1}}=-\overline{\ln t}
$$




$$
\begin{gathered}
\frac{\lambda_{1}-1}{c \lambda_{2}}=-\overline{t^{c}} \\
\frac{\lambda_{1}-1}{c \lambda_{2}^{2}}=-\left(\overline{\left.t^{c}\right)^{2}}\right.
\end{gathered}
$$

If $c=2$, the IUH derived by Lienhard (1964) is

$$
h(t)=\frac{1}{k \Gamma\left(\frac{3}{2}\right)}\left(\frac{3}{2}\right)^{3 / 2}\left(\frac{t}{k}\right)^{2} \exp \left[-\frac{3}{2}\left(\frac{t}{k}\right)^{2}\right]
$$

Using Eq. (41) in Eq. (36), the runoff hydrograph can be determined. Using an expression for $c(t)$ and Eq. (38) sediment discharge can be determined. Entropy-based approaches to determining sediment concentration in open channels were developed by Chiu et al. (2000), Choo (2000), and Cui and Singh (2014). These authors showed that the entropy-based equations predicted sediment concentration better than did empirical or hydraulicsbased equations. Cui and Singh (2014) surveyed various formulations for sediment concentration.

Table 1. Information on Watersheds Selected

\begin{tabular}{lccccc}
\hline Watershed & Location & $\begin{array}{c}\text { Period of } \\
\text { record }\end{array}$ & $\begin{array}{c}\text { Area } \\
\left(\mathrm{m}^{2}\right)\end{array}$ & $\begin{array}{c}\text { Average } \\
\text { annual } \\
\text { precipitation } \\
(\mathrm{mm})\end{array}$ & $\begin{array}{c}\text { Average } \\
\text { annual } \\
\text { runoff } \\
(\mathrm{mm})\end{array}$ \\
\hline Walnut & 63.102 & $1998-2012$ & 14,569 & 263 & 18.3 \\
Gulch & 63.103 & $1995-2012$ & 36,826 & 267 & 18.8 \\
& 63.104 & $1996-2012$ & 45,325 & 263 & 10.7 \\
& 63.105 & $1996-2012$ & 1,821 & 267 & 26.4 \\
& 63.106 & $1996-2012$ & 3,440 & 263 & 23.8 \\
& 63.112 & $1995-2012$ & 18,616 & 298 & 8.2 \\
Santa & 63.121 & $1995-2012$ & 54,228 & 269 & 14 \\
Rita & 76.1 & $1975-2012$ & 16,349 & 418 & 10.9 \\
& 76.2 & $1975-2012$ & 17,685 & 428 & 18.3 \\
& 76.3 & $1975-2012$ & 27,559 & 418 & 27.2 \\
& 76.4 & $1975-2012$ & 19,749 & 427 & 17.5 \\
& 76.5 & $1976-2012$ & 40,185 & 431 & 16.7 \\
& 76.6 & $1976-2012$ & 30,756 & 438 & 1.6 \\
& 76.7 & $1977-2012$ & 10,643 & 440 & 25.2 \\
& 76.8 & $1976-2012$ & 11,210 & 435 & 30.1 \\
\hline
\end{tabular}

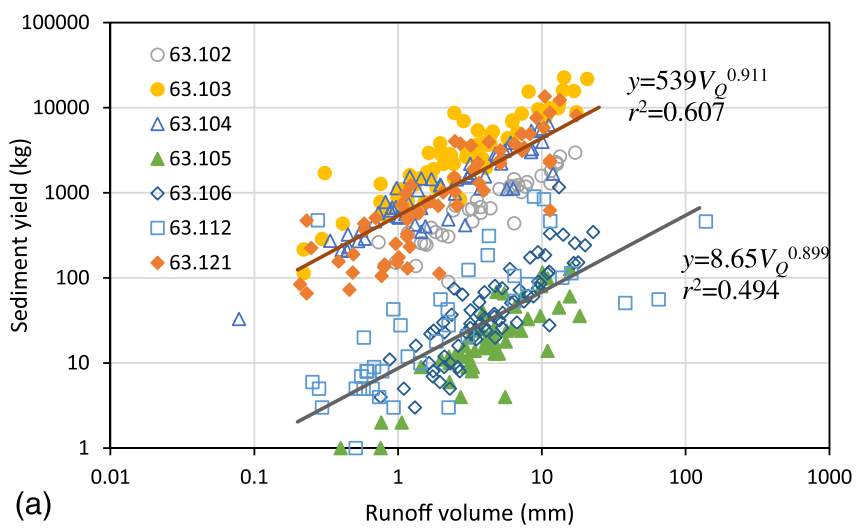

Fig. 1. Relationship between sediment yield and runoff volume for (a) Walnut Gulch; (b) Santa Rita

\section{Derivation of IUSG by Entropy Theory}

In this case, IUSG is derived using the entropy theory. First, a word must be said about ESEI. For a given storm, the amount of sediment generated, or sediment yield, can be determined using the sediment yield-runoff relation discussed in the previous section. ESEI is estimated by dividing the sediment yield by the duration of rainfall excess. This suggests that ESEI is a function of rainfall excess. Chen and Kuo (1986) expressed this function as a power function (ESEI $=a I^{b}$, where $a$ and $b$ are parameters), but it has not been adequately verified. It may be noted that IUSG has the same dimension as IUH. Therefore, the same framework can be employed to derive IUSG using entropy theory and so will not be repeated. Once $h_{s}(t)$ is determined, Eq. (37) is employed to determined $Q_{s}(t)$.

\section{Evaluation}

\section{Watersheds and Data}

To evaluate sediment graph models, data from 15 watersheds, 7 within the Walnut Gulch (63) and 8 within the Santa Rita (76) located in southern Arizona, operated by the USDA-Southwest Watershed Research Center, were used. The mean annual temperature is approximately $18^{\circ} \mathrm{C}$ and the average maximum temperature occurs in June. Precipitation is concentrated during JulySeptember, hence channels are dry approximately $99 \%$ of the time (Nearing et al. 2007). The seven subwatersheds within the Walnut Gulch watershed, designated as 63.102, 63.103, 63.104, 63.105, 63.106, 63.112, and 63.121, have a long-term sediment database. The first five watersheds are located in Lucky Hills, where the vegetation is predominantly desert shrubs. Watershed 63.112 is located in Kendall, which has a higher elevation in the Walnut Gulch watershed. Vegetation in Kendall is dominated by grass and forbs. Santa Rita is a much smaller watershed compared to Walnut Gulch, and the eight subwatersheds selected are closer to each other. Watersheds 76.1-76.4 are located in the lower portion of the Santa Rita, which is dominated by shrub, while Watersheds 75.5-75.8 are located in the grass-dominated upper portion. Additional information about these subwatersheds, such as area, average annual rainfall, and runoff, is given in Table 1 .

\section{Sediment Graph}

The relationship between sediment yield and runoff volume given by Eq. (4) was plotted (Fig. 1), and a best-fit line was determined using the least-squares method. Data from Walnut Gulch appeared

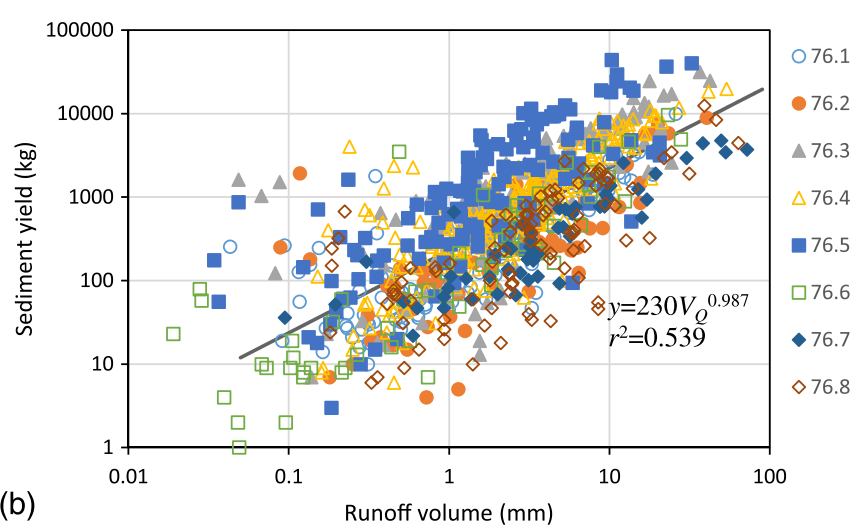


Table 2. Computed Values of Parameters for Sediment Yield

\begin{tabular}{lccccccccc}
\hline & & \multicolumn{3}{c}{ Least-squares method } & & \multicolumn{3}{c}{ Entropy method } \\
\cline { 3 - 5 } \cline { 7 - 9 } Watershed & Location & $a$ & $b$ & $r^{2}$ & & $a$ & $b$ & $r^{2}$ \\
\hline Walnut & 63.121 & 539 & 0.911 & 0.626 & 0.607 & & 438 & 1.204 & 0.613 \\
Gulch & 63.102 & & & 0.914 & & & & 0.917 \\
& 63.103 & & & 0.798 & & & & 0.789 \\
& 63.104 & & & 0.734 & & & & 0.720 \\
& 63.112 & 8.65 & 0.899 & 0.092 & 0.494 & & 8.723 & 0.752 & 0.108 \\
& 63.105 & & & 0.481 & & & & 0.488 \\
& 63.106 & & & 0.340 & & & & 0.338 \\
Santa & 76.1 & 230 & 0.987 & 0.757 & & 160 & 1.609 & 0.831 \\
Rita & 76.2 & & & 0.776 & & & 0.742 \\
& 76.3 & & & 0.764 & & & 0.715 \\
& 76.4 & & & 0.839 & & & 0.710 \\
& 76.5 & & & 0.461 & & & 0.411 \\
& 76.6 & & & 0.683 & & & 0.652 \\
& 76.7 & & & 0.833 & & & 0.700 \\
& 76.8 & & & 0.602 & & & 0.521 \\
\hline
\end{tabular}

to exhibit two significant groupings: one group consisted of data from Watersheds 63.102, 63.103, 63.104, and 63.121, and the other group consisted of the rest. The first group produced more sediment than the second one. Nearing et al. (2007) mentioned that Watersheds 63.102, 63.103, 63.104, and 63.121 are drained by well-developed, incised channel networks that can deliver eroded sediment efficiently to the outlets, while Watersheds 63.105 and 63.106 do not have incised channels, and hence sediment transport is slow. Watershed 63.112 is drained by concentrated flow paths that terminate in a swale above the outlet. Hence, regression of sediment yield on runoff volume was fitted separately for two groups, as shown in Fig. 1(a), with $r^{2}$ as 0.607 and 0.494 , respectively. On the other hand, one regression fit sufficed for all observed sediment data from Santa Rita watersheds.

Next, regression parameters were also determined by the entropy method given by Eq. (22). Three representative watersheds, 63.121, 63.112, and 76.1, were used to compute the parameters, which are given in Table 2 and plotted in Fig. 2. The parameter values determined by the entropy method were similar to those by the least-squares method. Comparing the $r^{2}$ values, it was observed that the entropy method was either comparable to or better than the least-squares method. The parameters determined for the three representative watersheds were employed to determine sediment graphs for the remaining watersheds. Fig. 3 shows the regression for Watershed 63.121 with parameter values obtained using the data from Watersheds 63.102, 63.103, and 63.104, and for Watershed 76.1 it was done using the data from Watersheds $76.2,76.4,76.6$, and 76.7. The $r^{2}$ values were generally larger than 0.5 and were similar to those of the least-squares method, showing the validity of the entropy method.

\section{IUH and IUSG}

To determine sediment discharge, IUH and IUSG were first determined using the entropy method. Assuming $c=2$, IUH and IUSG were obtained from Eq. (44) with parameter $k$ estimated from the lag time between the peak runoff or sediment discharge and the center of rainfall. Fig. 4 plots IUH and IUSG obtained for Watershed 63.102, where the lag time between peak runoff and the center of rainfall was $16 \mathrm{~min}$. In addition, the lag time between the peak sediment discharge and the center of rainfall was 21 min. Fig. 4 shows a plot of IUH and IUSG of Watershed
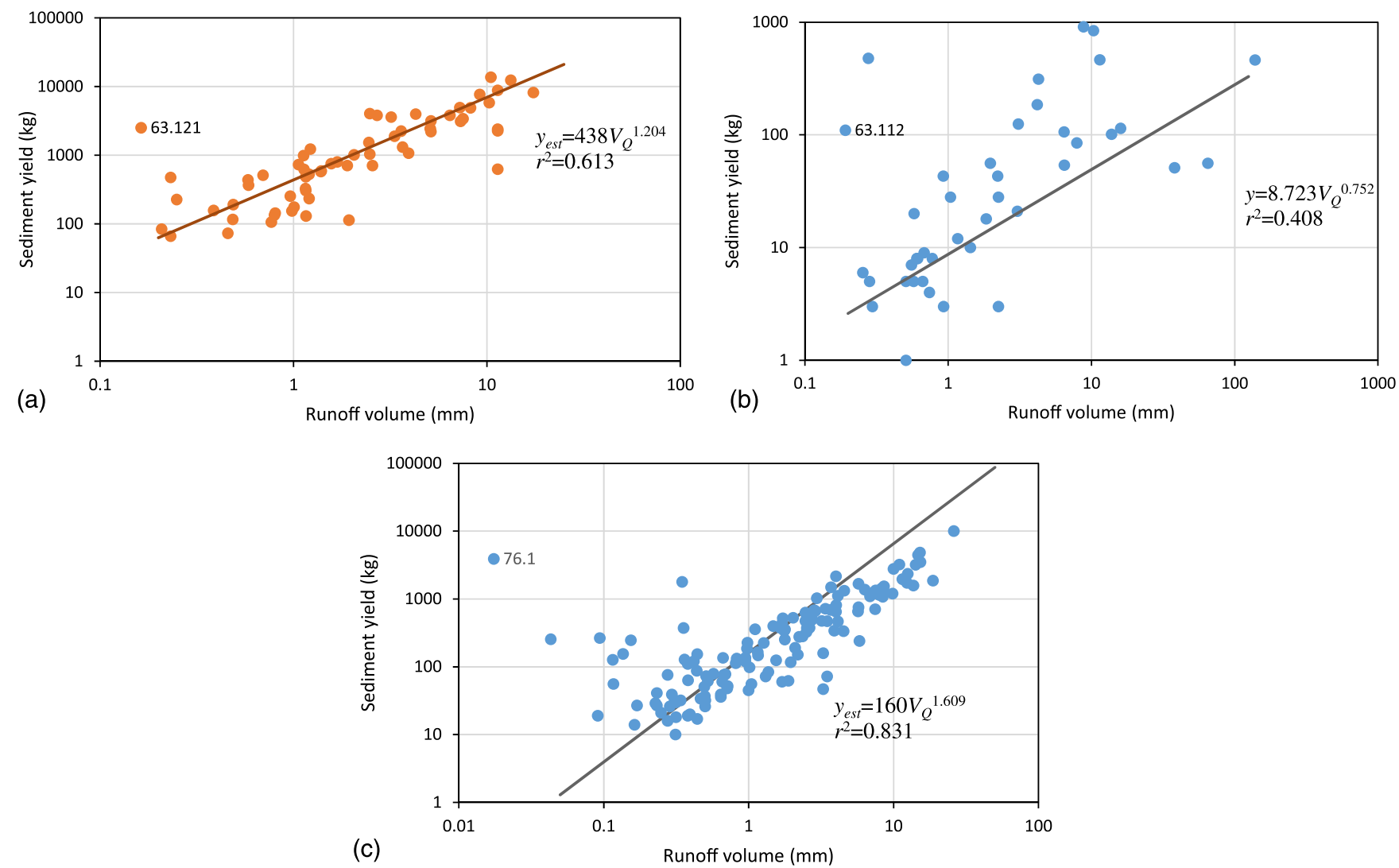

Fig. 2. Regression fit by entropy method for (a) Watershed 63.121; (b) Watershed 63.112; (c) Watershed 76.1 

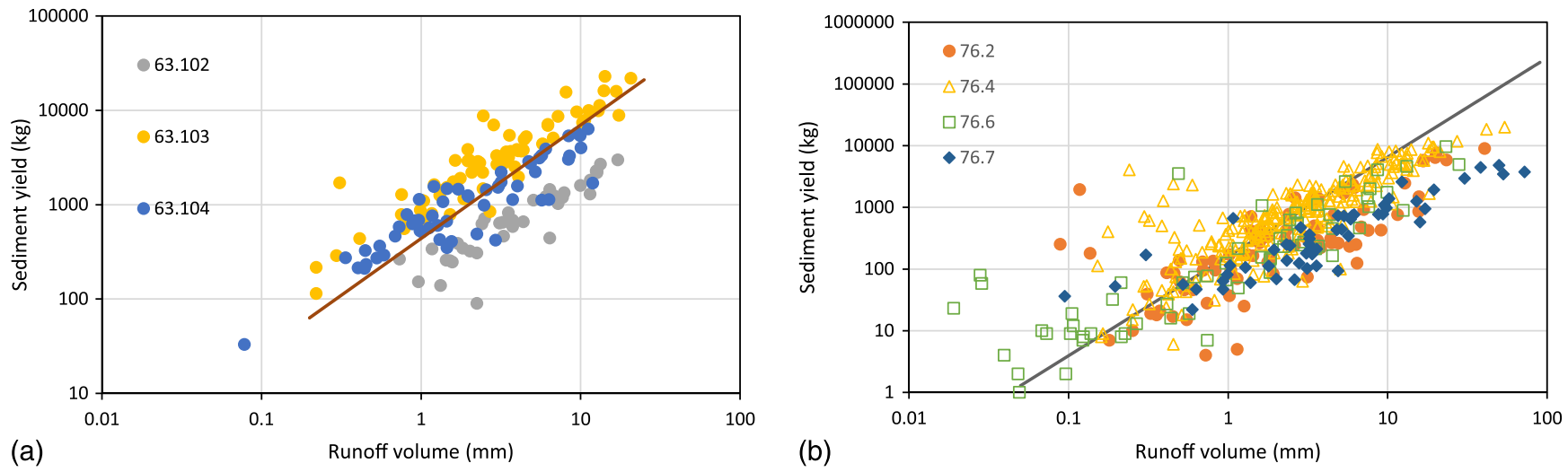

Fig. 3. Verification of regression method by entropy method

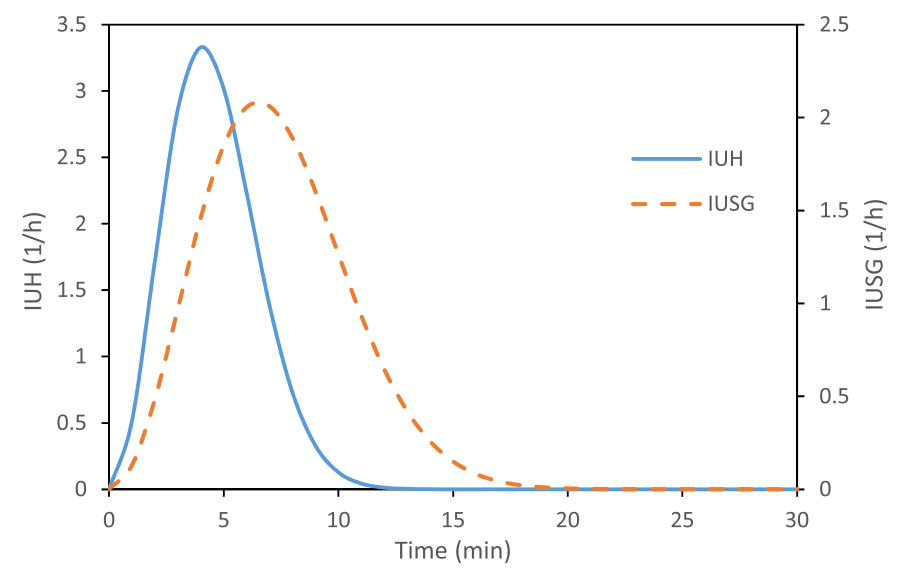

Fig. 4. IUH and IUSG estimated for Watershed 63.102

63.102, which suggests that transport of sediment was slower than runoff, and the peak sediment discharge occurred later than peak runoff.

Fig. 5 shows the runoff hydrograph obtained from the IUH using Eq. (36) for a storm event on July 3, 2012. The runoff hydrograph fitted the observed hydrograph well, where the root-meansquare error (RMSE) was found to be $4.47 \mathrm{~mm} / \mathrm{h}$, and $r^{2}$ was as high as 0.820 . However, the determined runoff started approximately 3 min earlier than the observed hydrograph, and peak runoff occurred 2.5 min later than the observed value. The runoff generated from Watershed 76.1 for the storm event of September 9, 2011, is also plotted in Fig. 5, where peak runoff agreed with the observed value, although the hydrograph was somehow left-skewed compared to the observed hydrograph.

Sediment concentration can also be obtained from Fig. 5, which shows that sediment seems to be more concentrated during peak runoff. The sediment concentration time series is highly stochastic and uncertain in these plots. Unfortunately, limited sediment concentration data are available to determine further characteristics. Sediment discharge can be computed by either multiplying sediment concentration with runoff computed from IUH or integrating IUSG with effective sediment erosion intensity.

\section{Effective Sediment Erosion Intensity}

Before determining the sediment discharge, one may want to check the relationship between ESEI and rainfall intensity (I). Thus, in Fig. 6, ESEI was fitted to rainfall intensity by a power law, using data from Watersheds 63.102 and 76.1. It seems that the erosion intensity of Watershed 76.1 was less dependent on rainfall. The power function fitted Watershed 63.102 well with $r^{2}$ as 0.894 , but it was not very satisfactory for Watershed 76.1. Although both watersheds are vegetated by shrubs, the channel network of Watershed 63.102 is more efficient for sediment transport, which may explain the high correlation between ESEI and I. This may influence the accuracy of the estimation of sediment discharge when using the IUSG method.
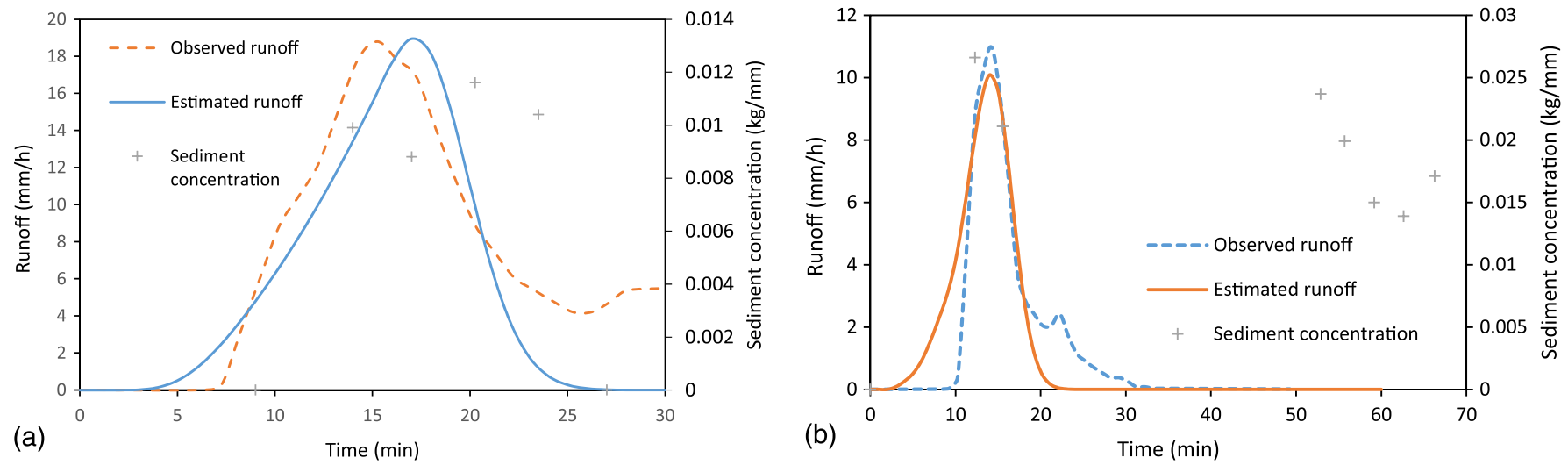

Fig. 5. Runoff hydrograph estimated for Watersheds 63.102 and 76.1 

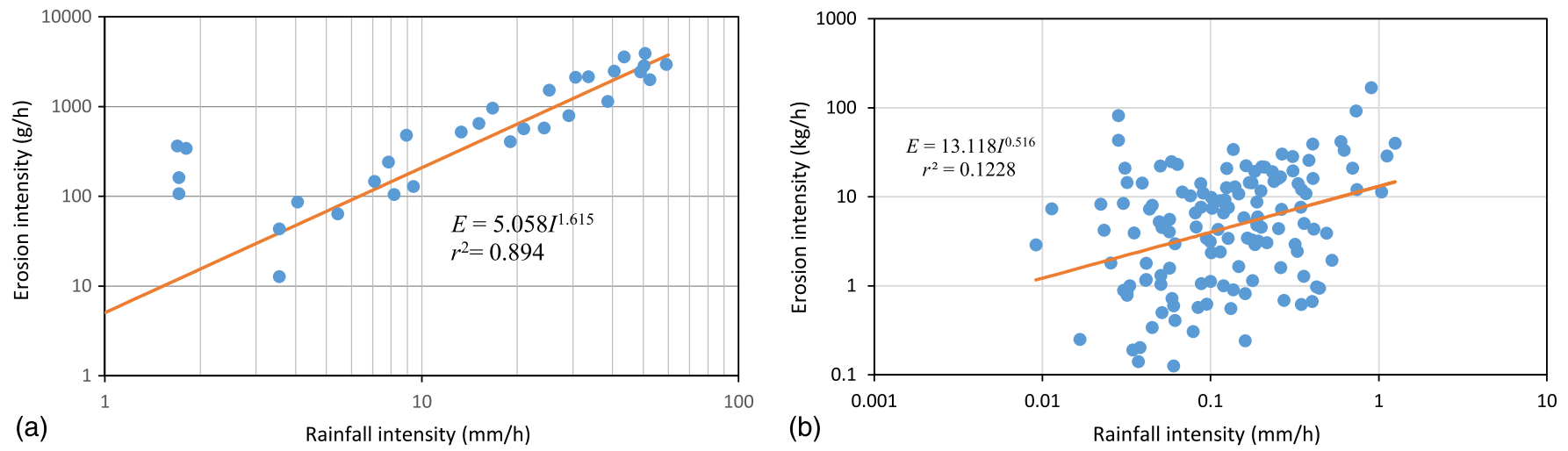

Fig. 6. Relationship between ESEI and I for (a) Watershed 63.102; (b) Watershed 76.1
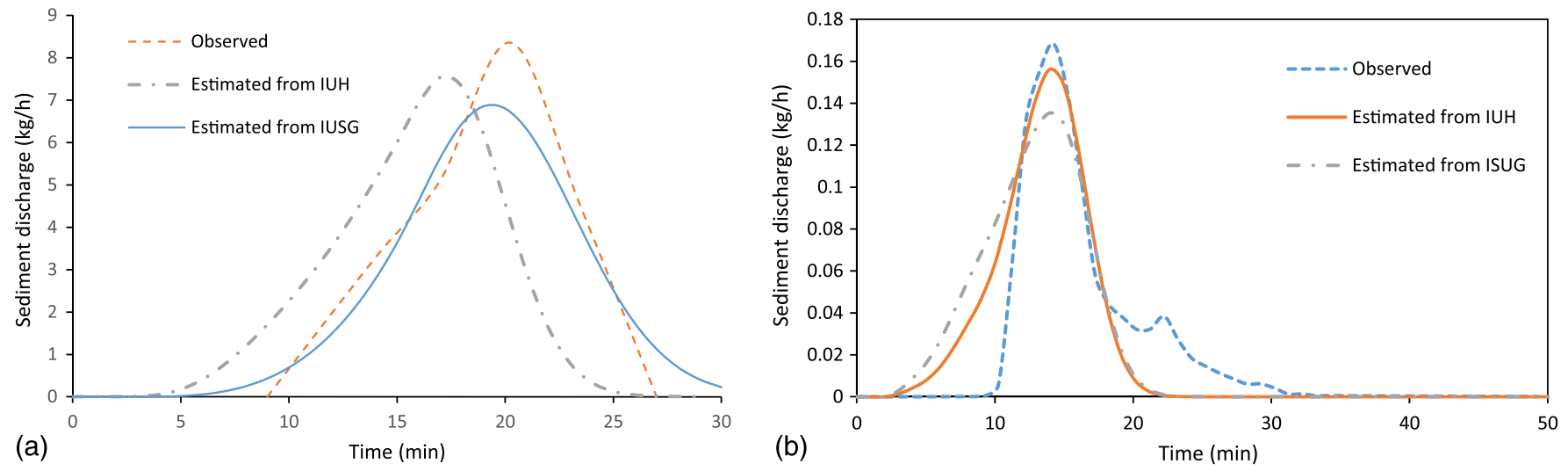

Fig. 7. Estimated sediment discharge for (a) Watershed 63.102; (b) Watershed 76.1

\section{Sediment Discharge Graph}

Sediment discharge was computed for each watershed by combining a runoff hydrograph with sediment concentration as well as by convoluting IUSG with ESEI. Fig. 7 plots sediment discharge computed using both IUH and IUSG (Fig. 5) for Watersheds 63.102 and 76.1, respectively. It can be seen from Fig. 7(a) that sediment discharge determined by IUH was 3 min earlier than observed discharge, while that determined by IUSG was closer to the observed peak time. But the peak sediment discharge value determined by IUH of $7.54 \mathrm{~kg} / \mathrm{h}$ was closer to the observed value of $8.35 \mathrm{~kg} / \mathrm{h}$ than that of $6.85 \mathrm{~kg} / \mathrm{h}$ by IUSG. The computed error in sediment discharge is shown in Table 3, which shows that the IUSG method gave higher $r^{2}$ and RMSE than the IUH method.
Thus, for Watershed 63.102, the IUSG method is recommended over the IUH method. In contrast, for Watershed 76.1, the IUH method, with an $r^{2}$ of 0.841 , seemed to provide a better prediction than the IUSG method, with an $r^{2}$ of 0.720 . It can be seen from Fig. 7(b) that for the storm event of September 9, 2011, at Watershed 76.1, the peak sediment discharge occurred simultaneously with peak runoff. Thus, both the IUH and IUSG methods gave correct predictions of the peak time. However, the sediment discharge computed by the IUSG method was influenced by a lower correlation between ESEI and rainfall intensity, as shown in Fig. 6(b). That may explain why IUH performed better for Watershed 76.1.

It may now be interesting to examine how the IUH and IUSG methods would perform for ungauged watersheds. The IUH and IUSG obtained for Watersheds 63.102 and 76.1 were used for

Table 3. Computed Errors for Runoff and Sediment Discharge

\begin{tabular}{|c|c|c|c|c|c|c|c|}
\hline \multirow[b]{2}{*}{ Watershed } & \multirow[b]{2}{*}{ Event } & \multicolumn{2}{|c|}{ Runoff } & \multicolumn{2}{|c|}{ Sediment discharge by IUH } & \multicolumn{2}{|c|}{ Sediment discharge by IUSG } \\
\hline & & $\operatorname{RMSE}(\mathrm{mm} / \mathrm{h})$ & $r^{2}$ & $\operatorname{RMSE}(\mathrm{kg} / \mathrm{h})$ & $r^{2}$ & $\operatorname{RMSE}(\mathrm{kg} / \mathrm{h})$ & $r^{2}$ \\
\hline 63.102 & July 3, 2012 & 4.47 & 0.820 & 1.55 & 0.579 & 0.38 & 0.972 \\
\hline 63.102 & June 20, 2000 & 5.28 & 0.791 & 0.93 & 0.625 & 0.46 & 0.911 \\
\hline 63.103 & July 3, 2012 & 2.83 & 0.803 & 0.98 & 0.804 & 0.25 & 0.832 \\
\hline 63.121 & July 3, 2012 & 1.89 & 0.698 & 3.04 & 0.523 & 3.25 & 0.528 \\
\hline 76.1 & September 9, 2011 & 1.08 & 0.846 & 0.17 & 0.841 & 0.02 & 0.720 \\
\hline 76.1 & August 18, 2011 & 1.45 & 0.799 & 3.20 & 0.828 & 3.05 & 0.751 \\
\hline 76.5 & August 18, 2011 & 2.56 & 0.858 & 12.57 & 0.812 & 12.98 & 0.800 \\
\hline
\end{tabular}

Note: RMSE = root-mean-square error; IUH = instantaneous unit hydrograph; IUSG = instantaneous unit sediment graph. 

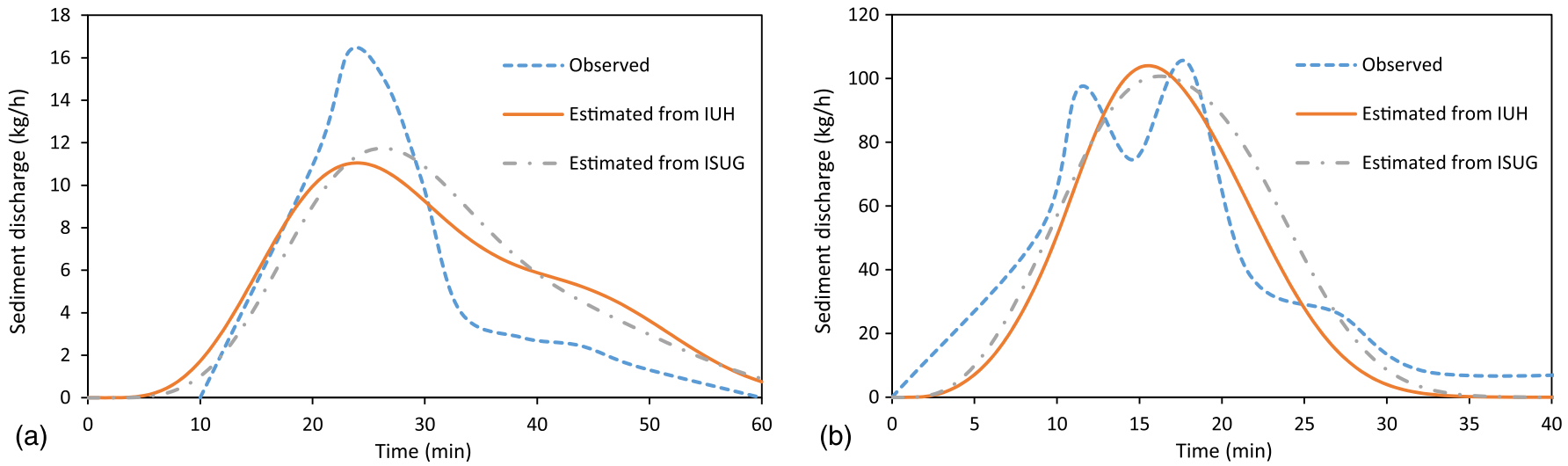

Fig. 8. Estimation of sediment discharge for ungauged watersheds: (a) Watershed 63.103; (b) Watershed 76.5

nearby watersheds, which were assumed to be ungauged. Fig. 8 shows the prediction of sediment discharge for ungauged Watersheds 63.103 and 76.5 using parameters estimated from Watersheds 63.102 and 76.1, respectively. The peak time determined for sediment discharge from Watershed 63.103 for the storm event of July 3, 2012, was 1 min early using the IUH method and 2 min late using the IUSG method. The computed RMSE and $r^{2}$ in Table 3 show that the IUSG method was slightly better for this watershed. However, the sediment discharge predicted for Watershed 76.5 using the parameters of Watershed 76.1 was reasonable for both methods, with $r^{2}$ for the two methods being 0.812 and 0.800 .

More events were used and errors of prediction were computed, as listed in Table 3. It can be seen that a low $r^{2}$ computed for runoff lowered the accuracy of sediment discharge by the IUH method. This is understandable since sediment discharge is computed from the runoff hydrograph and sediment concentration. In general, for subwatersheds in Walnut Gulch (63), where the eroded sediment is transported efficiently, $r^{2}$ was generally low for the IUH method; thus, sediment discharge determined by the IUSG method was better. But for the subwatersheds from Santa Rita, the low correlation between ESEI and rainfall intensity influenced the accuracy of the IUSG method, where $r^{2}$ was slightly lower for the IUSG method. Thus, the IUH method is recommended for the Santa Rita watersheds.

\section{Conclusions}

The following conclusions are drawn from this study:

1. The sediment yield fits runoff volume as a power law, and nearby watersheds share similar values of exponents. The entropy theory provides an efficient way to determine the parameters of the power relation, and parameter values thus obtained are comparable to those obtained by the least-squares method.

2. Sediment discharge is computed by the entropy method in two ways: the IUH method and the IUSG method. Both methods have their advantages and disadvantages.

3. The accuracy of prediction of sediment discharge by the IUH method is linked to the accuracy of IUH.

4. The accuracy of prediction of sediment discharge by the IUSG method is linked to the accuracy of effective erosion intensity.

5. The IUH method is comparable to the IUSG method when peak runoff and peak sediment discharge occur at the same time. Otherwise, the IUH method predicts the peak of sediment discharge earlier than the observed value.
6. Although the IUSG method is accurate in determining the time of peak sediment discharge, its accuracy is affected by the regression of ESEI on rainfall intensity.

\section{References}

Chen, V. J., and Kuo, C. Y. (1986). "A study of synthetic sediment graphs for ungagged watersheds." J. Hydrol., 84(1-2), 35-54.

Chiu, C. L. (1987). "Entropy and probability concepts in hydraulics." J. Hydraul. Eng., 10.1061/(ASCE)0733-9429(1987)113:5(583), 583-600.

Chiu, C. L., Jin, W., and Chen, Y. C. (2000). "Mathematical models of distribution of sediment concentration." J. Hydraul. Eng., 10.1061/ (ASCE)0733-9429(2000)126:1(16), 16-23.

Choo, T. H. (2000). "An efficient method of the suspended sedimentdischarge measurement using entropy concept." Water Eng. Res., 1(2), 95-105.

Cui, H., and Singh, V. P. (2014). "Suspended sediment concentration in open channels using tsallis entropy." J. Hydrol. Eng., 10.1061/ (ASCE)HE.1943-5584.0000865, 966-977.

De Araujo, J. C. (2007). "Entropy-based equation to assess hillslope sediment production." Earth Surf. Processes Landforms, 32(13), 2005-2018.

Figueiredo, E. E., and Bathurst, J. C. (2007). "Runoff and sediment yield predictions in a semiarid region of Brazil using SHETRAN." IAHS Decade on: Prediction in Ungaged Basins, D. Schertzer, P. Hubert, S. Koide, and K. Takeuchi, International Association of Hydrological Sciences, Wallingford, U.K., 258-266.

Foster, G. R., and Lane, L. J. (1983). "Erosion by concentrated flow in farm fields." Proc., D.B. Simons Symp. on Erosion and Sedimentation, Colorado State Univ., Fort Collins, CO, 9.56-9.82.

Hairsine, P. B., and Rose, C. W. (1992). "Modeling water erosion due to overland flow using physical principles. 1: Sheet flow." Water Resour. Res., 28(1), 237-243.

Jaynes, E. T. (1957a). "Information theory and statistical mechanics. I." Phys. Rev., 106(4), 620-630.

Jaynes, E. T. (1957b). "Information theory and statistical mechanics. II." Phys. Rev., 108(2), 171-190.

Jaynes, E. T. (1982). "On the rationale of maximum entropy methods." Proc. IEEE, 70(9), 939-952.

Jin, D., Chen, H., and Guo, Q. (1999). "A preliminary experimental study on non-linear relationship between sediment yield and drainage network development." Int. J. Sediment Res., 14(2), 9-18.

Kirkby, M. J., et al. (2002). "MEDRUSH-a basin scale physically based model for forecasting runoff and sediment yield." Chapter 16, N: Mediterranean desertification: A mosaic of processes and responses, N. S. Geeson, C. J. Brandt, and J. B. Thornes, eds., Wiley, Chichester, U.K., 203-207. 
Lane, L. J., and Nearing, M. A., eds. (1989). "Water erosion prediction project: Hillslope profile model documentation." NSERL Rep., USDA-ARS, West Lafayette, IN.

Lienhard, J. H. (1964). "A statistical mechanical prediction of the dimensionless unit hydrograph.” J. Geophys. Res., 69(24), 5231-5238.

Morgan, R. P. C., et al. (1998). "The European soil erosion model (EUROEM). A Process based approach for predicting soil loss from fields and small catchments." Earth Surf. Processes Landforms, 23(6), 527-544.

Nearing, M. A., Nichols, M. H., Stone, J. J., Renard, K. G., and Simanton, J. R. (2007). "Sediment yields from unit-source semiarid watersheds at Walnut Gulch." Water Resour. Res., 43(6), W06426.

Nunes, J. P., de Lima, J. L. M. P., Singh, V. P., de Lima, M. I. P., and Vieira, G. N. (2006). "Numerical modeling of surface runoff and erosion due to moving storms at the drainage basin scale." J. Hydrol., 330(3-4), 709-720.

Renard, K. G., Foster, G. R., Weesies, G. A., McCool, D. K., and Yoder, D. S. (1993). "Predicting soil erosion by water-A guide to conservation planning with the revised universal soil loss equation (RUSLE)." Agricultural Research Service, USDA, Washington, DC.

Rendon-Herrero, O. (1974). "Estimation of washload produced by certain small watersheds." J. Hydraul. Div., 109(HY7), 835-848.

Rendon-Herrero, O. (1978). "Unit sediment graph.” Water Resour. Res., 14(5), 889-901.

Rendon-Herrero, O., Singh, V. P., and Chen, V. J. (1980). "ER-ES watershed relationship." Proc., Int. Symp. on Water Resources Systems, Vol. 1, Univ. of Roorkee, Roorkee, India, II-8-41-7.

Shannon, C. E. (1948). "A mathematical theory of communication." Bell Syst. Tech. J., 27(3), 379-423.

Sharma, T. C., and Dickinson, W. T. (1979a). "Unit step and frequency response functions applied to the watershed fluvial system." J. Hydrol., 40(3-4), 323-335.

Sharma, T. C., and Dickinson, W. T. (1979b). "Discrete dynamic model of watershed sediment yield." J. Hydraul. Div., 105(HY5), 555-571.

Singh, V. P. (1983). "Analytical solutions of kinematic equations for erosion on a plane: 2. Rainfall of finite duration." Adv. Water Resour., 6(2), 88-95.

Singh, V. P. (1989). Hydrologic systems: Watershed modeling, Prentice Hall, Englewood Cliffs, NJ.

Singh, V. P. (1998). Entropy-based parameter estimation in hydrology, Kluwer, Boston.
Singh, V. P. (2010a). "Entropy theory for derivation of infiltration equations." Water Resour. Res., 46(3), W03527.

Singh, V. P. (2010b). "Tsallis entropy theory for derivation of infiltration equations." Trans. ASABE, 3(2), 447-463.

Singh, V. P. (2010c). "Entropy theory for movement of moisture in soils." Water Resour. Res., 46, W03516.

Singh, V. P. (2011). "An IUH equation based on entropy theory." Trans. ASABE, 54(1), 1-10.

Singh, V. P., Baniukiewicz, A., and Chen, V. J. (1982). "An instantaneous unit sediment graph study for small upland watersheds." Modeling components of hydrologic cycle, V. P. Singh, ed., Water Resources Publications, Littleton, CO, 539-554.

Singh, V. P., and Chen, V. J. (1982). "On the relation between sediment yield and runoff volume." Modeling components of hydrologic cycle, V. P. Singh, ed., Water Resources Publications, Littleton, CO, 555-570.

Singh, V. P., and Krstanovic, P. F. (1987). "A stochastic model for sediment yield using the principle of maximum entropy." Water Resour. Res., 23(5), 781-793.

Singh, V. P., and Regl, R. R. (1983). "Analytical solutions of kinematic equations for erosion on a plane: 1. Rainfall of infinite duration." $A d v$. Water Resour., 6(1), 2-10.

Smith, R. E., Goodrich, D. C., Woolhiser, D. A., and Unkrich, C. L. (1995). "KINEROS: A kinematic runoff and erosion model." Chapter 20, Computer models of watershed hydrology, V. P. Singh, Water Resources Publications, Littleton, CO, 697-732.

Soil Conservation Society of America. (1977). "Soil erosion: Prediction and control." Proc., National Conf. on Soil Erosion, Purdue Univ., West Lafayette, IN.

Srivastava, P. K., Rastogi, R. A., and Chauhan, H. S. (1984). "Prediction of storm sediment yield from a small watershed." J. Agric. Eng., 21(1-2), $121-126$.

Tyagi, J. V., Mishra, S. K., Singh, R., and Singh, V. P. (2008). "SCS-CN based time-distributed sediment yield model." J. Hydrol., 352(3-4), 388-403.

Williams, J. R. (1975). "Sediment routing for agricultural watersheds." Water Resour. Bull., 11(5), 965-974.

Williams, J. R. (1978). “Unit sediment graph.” Water Resour. Res., 14(5), 889-901.

Williams, J. R., and Berndt, H. D. (1977). "Sediment yield prediction based on watershed hydrology." Trans. ASAE, 20(6), 1100-1104.

Wischmeier, W. H., and Smith, D. D. (1978). Predicting rainfall erosion losses - A guide to conservation planning, USDA, Washington, DC. 